\title{
Homogenizing of Indian Diaspora in Transnational Contexts
}

\section{Dr. Abdul Wahab Siddiqui}

Asst. Professor

Department of English, MAJ University, Rampur UP (India)

E-mail: abdulwahabsiddiqui@gmail.com

\begin{abstract}
Homogenization, heterogeneity, hybridist and multiplicity are the characteristics of the diasporic cultures. Heterogeneity means the existence of differences and differential relationships among the Diasporas in the adopted country. For example, the South-Asian emigrants originated from diverse socio-cultural groupings and regions of South Asia. They carried with them their own linguistic, religious as well as other differences. Hybridist suggests adjustment, adaptation and accommodation of the immigrant practices to the dominant forms. The social articulation of difference, from the minority perspective, is a complex ongoing negotiation that seeks to authorize cultural hybrid ties that emerge in moments of historical transformation.
\end{abstract}

Keywords: Homogenization, Heterogeneity, Diaspora, Multiplicity

\section{INTRODUCTION}

Multiplicity conveys how subjects located within social relations are determined, in multiple ways, by the contradictions of capitalism, patriarchy and race relations. If the minority immigrant cultures are perpetually changing in their composition, configuration and practices as well as in their relations to one another; the dominant culture, too, is affected by the process. It is the relational balancing between the two cultures the host and the diaspora. Diasporic cultural identity teaches us that cultures are not preserved by being protected from mixing. But they may continue as a product of such a mixing.

Before the advent of the World Wide Web, the Diaspora communities living touch with the motherland was a problem, which caused their emotional state of mind. Now these communities can turn to cyber technology in order to connect with their motherland in a virtual sense. The homeland becomes at once remote and accessible due to cyber communication. There are many contexts in which 'technospheric' space is used for positive ends to promote a better and more inclusive vision of the nation and its constituent parts. It is 
Journal of Advance Research in Science and Social Science (JARSSC)

Official Publication of Indian Mental Health \& Research Centre

DOI: $10.46523 /$ jarssc. 03.02 .06

Multidisciplinary, Open Access
ISSN: 2582-2004

Volume 03, Issue 02

also true that this space can be deployed for markedly different political ends. Cyberspace can be used to consolidate and reaffirm communal links among the Diaspora communities. The parameters of nationhood might be altered and new class divides might emerge challenging the basic assumptions about home and national belonging due to cyber space. Now the historical and geographical bond between the Diaspora communities has been strengthened by the modem transportation and communication technologies. It is imperative that we should conduct further research in to various aspects of the use of communication and other technologies by the members of the diaspora and the impacts of these technologies on heritage culture as well as ethnic identity.

The sun never sets on the South Asian Diaspora as the twenty million strong South Asian Diaspora is spread over a hundred and ten countries, across all the oceans and continents. India Diaspora is the second largest diaspora from Asia, next only to China. Their Indian identity is characterized by their Indian origin, their consciousness of Indian cultural heritage and their attachment to India. The trajectory of the Indian Diaspora can be viewed in terms of three waves. The first wave consisted of indentured labour that went to Fiji, South Africa, Martinique, Surinam, Angola, Mozambique and other places. The second wave of migrants ventured out into the neighbouring West Asian and Gulf countries, as professionals, artisans, traders and factory workers in search of opportunities for career advancement. Some members of this Diaspora migrated to the US as well as the UK. The current third wave consists of the professionals and the educated elite of India, who seek economic betterment in the most advanced countries of the world.

The Indian Diaspora plays an important role in and contributes to the development of the host countries as well as the homeland. For instance, the Indian Diaspora plays a positive role in enhancing India's bilateral political and economic relations with the countries of their residence. They can be a vibrant bridge between the two. The relationship of the Indian Diaspora with the parent society is characterized by the confluence and conflict of interests. In 2000, the Government of India appointed the High Level Committee on the Indian Diaspora in order to explore the possibilities of mutually beneficial relationship between the Indian Diaspora and India. After working for fifteen months and travelling to twenty countries, the committee - submitted the report. The report of 2001 contained the recommendations on the entire gamut of the collaboration, coordination and co- operation 
Journal of Advance Research in Science and Social Science (JARSSC)

Official Publication of Indian Mental Health \& Research Centre

DOI: $10.46523 /$ jarssc.03.02.06

Multidisciplinary, Open Access
ISSN: 2582-2004

Volume 03, Issue 02

between the Indian Diaspora and the Government of India for an environment conducive to their mutually beneficial relationship.

Following the conclusions and recommendations in the aforesaid report, the Government of India has offered dual citizenship to those members of the Indian Diaspora who have acquired the citizenship of the US, the UK, the European Union, Canada, Australia, Singapore, Malaysia, Thailand, Japan, and New Zealand, leaving out the chunk of the Diaspora in the Gulf, Myanmar, Trinidad, Tobago, Fiji, Guyana and other places. The dual citizenship is to make the Diaspora a more active participant in the national affairs of India. But very few groups are entitled to it in view of the restrictions. By contrast, China has offered it to all non-resident Chinese without selection. From another point of view, the dual citizens might be looked at with suspicion in their adopted countries if the dual citizenship involves the element of loyalty. For some reasons or other, the, Indian Diaspora in South Africa expressed its reservations about the offer of dual citizenship. In fact, the measures taken by the Indian Government, in respect of the political and other rights of the NR is, have not come up to their expectations. In addition, there is nothing to write home about the Indian Government's diplomatic and economic support to some sections of the Indian Diaspora in their hour of crisis. These are some of the issues, thrown up by the new development vis-a-vis the Indian Diaspora, which call for critical attention,

It is also equally true that it has been attempted to investigate the complex phenomenon of the South Asian Diaspora at the macro level to some extent. But the region wise studies of this phenomenon are yet to be undertaken at the micro level. As a matter of fact, different regional identities of the Indian Diaspora shape the national identity. Studies of various Diaspora castes, communities and professional groups from the various regions of the nation, based on regional sources, might go a long way towards interpreting the forces and factors of the Diaspora. Their contribution to the economic development of their specific areas can make a fascinating study. For instance, the migrant castes as well as communities from North Gujarat have generously subscribed to the cause of education in the towns and villages therein. It is noteworthy that the Punjabi Diaspora has received considerable attention. But the Diasporas from Gujarat, Bihar, Eastern Uttar Pradesh, Karnataka, Tamil Nadu and Kerala merit the same attention. The complexities of the Indian Diaspora in particular and Diaspora in general can be unraveled by investigation into the Indian rural émigré population The 
Indian Diaspora has made a substantial contribution to the literary output of their host countries. Some eminent creative writers have been accorded recognition, for their oeuvres at home and abroad. If we look at the courses in Indian literature in any university abroad, most of the prescribed texts belong to Indian Diaspora literature. Hence, there is need to evaluate this literature. Neither a celebratory nor a derogatory approach to Indian Diaspora literature would suffice. Those literary texts, which sell India as a slice of exotica to the willing Western audience need to be safely ignored. Similarly the validity of the books which simply mystify or idealize India may be questioned as Diaspora literature.

It is also found that English has remained the medium of communication of majority of the Diaspora artists across the globe. They use a variety of English, depending on their intellectual, educational and linguistic background. Some of them have attempted to mould the medium to suit their creative complexity. In fact, it is this area that the critics and scholars require to explore with the tools as well as techniques offered by modern stylistics. Understandably, the stylistic studies of Indian Diaspora literature might sub serve the fashioning of the critical apparatus that is in the process.

Further, what is at present commonly considered as India Diaspora writing originates from the individuals from the Indian Diaspora people group, who have the felt involvement of the Diaspora. The vicarious experience of those inventive authors whose imagination grasps Indian Diaspora in their books may not be Jess critical. Further, as of late, there is a developing assortment of Diaspora writing in provincial dialects. This vernacular convention in this writing claims basic consideration. Moreover, as the understudies of Diaspora have no dependable basic system for Diaspora writing, they are inclined to examine Indian Diaspora as far as a solid structure, as is clear in a large portion of the examinations. Aside from the unobtrusive subjective varieties in the reasonableness of the Indian Diaspora in a similar host nation, getting from various elements, the diverse Indian diaspora networks living in the distinctive host nations are presented to various sorts of enthusiastic just as scholarly effects. Indian Diaspora writing catches such subtleties and amenities, which ought to connect with the consideration of the basic researchers for the investigation of the diaspora reasonableness. Similar technique is additionally recommended to ponder Indian Diaspora writing, at different dimensions, in different points of view and from different edges, which would give profitable contributions to the bit by bit rising ordinance of analysis in this space. One may 
Journal of Advance Research in Science and Social Science (JARSSC)

Official Publication of Indian Mental Health \& Research Centre

DOI: $10.46523 /$ jarssc. 03.02 .06

Multidisciplinary, Open Access
ISSN: $2582-2004$

Volume 03, Issue 02

think about culture, patriotism, ethnicity, race, sexual orientation, religion, legislative issues and society as respects this writing.

As indicated by Maharani Para jape, Professor of English, J .N. U., New Delhi, "a diasporic content can be inspected as far as area, separation and migration. Area is the country. Separation can be viewed as a break with the old personality and the development of another character." It would be a horrible ordeal. The following foundation is hybridist. It is a brilliant mean among contrast and absorption. Indeed, the outsiders modify and adjust to the new culture while protecting their legacy. As per Para jape, we discover two kinds of hybridist hostile to Indian hybridism and genius Indian heredity in the scholarly messages. Nevertheless, Indian diaspora writing may be assessed keeping in view the component of hybridists, far beyond different measurements. Besides, the artistic fault-finders may think about how the abstract writings consult between inquiries of independence, inquiries of Swaraj and inquiries of poise, of the diaspora as well as of the locals. Similarly, the pundits could grill the country depicted and the legislative issues of portrayal treated in the content. Most importantly, the relationship of the Diaspora with the country, as it rises at the social, social, mental, passionate and otherworldly dimensions in the content ought to be tended to.

India, being the home of the third biggest Diaspora on the planet, should advance a long haul national arrangement towards the Indian Diaspora, including the up to this point ignored under advantaged class in that. The Indian Diaspora is a worldwide substance with a worldwide character. What is required is a multi-pronged, dynamic and adaptable way to deal with the Diaspora and Diaspora writing. The Indian colleges can encourage this undertaking by empowering serious and broad diasporic learns at various dimensions. In such manner they may set up region think about focuses, sort out courses and symposia, offer the significant undergrad and postgraduate projects and prepare and refresh their libraries with the most recent asset material.

The about two million Indians who have moved to the U.S. in the course of the most recent thirty years shape a noteworthy Diasporic people group. They are not the same as prior worker bunches in being not devastated laborers but rather a profoundly instructed proficient tip top looking for expert and monetary chance. They have made their voices heard in business, governmental issues and social life, and have partaken significantly in the American 
Journal of Advance Research in Science and Social Science (JARSSC)

Official Publication of Indian Mental Health \& Research Centre

DOI: 10.46523 jarssc. 03.02 .06

Multidisciplinary, Open Access
ISSN: $2582-2004$

Volume 03 , Issue 02

dream. Yet, as completely as they are coordinating into America, they additionally keep up solid ties of marriage and connect back to their country, utilize their business and political associations with their very own advantage and that of loved ones in India. An investigation of the writing of this Indo-American diaspora gives a chance to perceiving how this gathering sees itself and how it sees its connections to America. In particular, it empowers us to perceive how these postcolonial Indians think about their awareness of way of life as a minority network, what techniques they utilize to distinguish the "home" abandoned and its proceeding with nearness in the mind, what the bursting impacts of movement are, and how another, coordinated social character rises.

Characterized in the least difficult terms, Asian American writing is composed by people of Asian plunge in the United States, not really natives. While a few scholars are fresh introductions, others have been occupants for a long time and some of the time their refrains for ages. Some have traveled to the United States by means of Africa or the obligated working class from the West Indies. Today, new types of colonization managed by the geopolitical and geo-monetary substances of an industrialist "new world request" keep on requiring movements and migrations from South Asia into North America. Similitudes of circumstances from the post-provincial figure of speech possess large amounts of such Asian American journalists the "trishanku" picture of being suspended between two universes and having a place with none; the insider-untouchable or "desh-pardesh" disorder; the job of memory, sentimentality and osmosis in their works are regularly found with striking likenesses. Additionally, Americans don't currently discuss absorption, the finished result of the blend procedure, yet of multiculturalism

\section{CONCLUSION}

Homogenization of the Diaspora life is impossible because of its varied and complex nature. Cultural identities undergo constant transformation. For example, the Indian immigrants from Africa go to Canada where they have to unlearn Africa and relearn Canada. Diasporic cultures include practices that are partly inherited, partly modified and partly invented. They are heterogeneous entities. These cultures are continually shifting under pressure from within and without. Ethnicity is always in a state of flux, far from being static, stagnant and unchangeable. A member of the 'Diaspora' is a citizen of the world, belonging everywhere 
Journal of Advance Research in Science and Social Science (JARSSC)

Official Publication of Indian Mental Health \& Research Centre

DOI: 10.46523 jarssc. 03.02 .06

Multidisciplinary, Open Access
ISSN: 2582-2004

Volume 03, Issue 02

and nowhere. History bears witness to the fact that identities, selves, traditions and natures do change with travels and travails.

\section{$\underline{\text { References: }}$}

Hall, S. (1990). Cultural identity and diaspora. In J. Rutherford (Ed.), Identity: Community, culture, difference (pp. 222-237). London: Lawrence \& Wishart.

Abu El-Haj N. The genetic reinscription of race. Annual Review of anthropology. 2007;36:283-300.

Cohen, R. 1997.Global Diaspora :An Introduction. London : UCLPress

Mishra, Vijay. 1996. "The Diasporic Imaginary: Theorising the Indian Diaspora." Textual Practice 10(3):421-452.

Leckie, Jacqueline. 2010. “A Long Diaspora Indian Settlement.” In India in New Zealand Local Identities, Global Relations, edited by SekharBandopadhyay, 45-63. Dunedin: Otago University Press.

Lessinger, Johanna. 2003. "Indian Immigrants in the United States The Emergence of a Transnational Population." In Culture and Economy in the Indian Diaspora, edited by Bhikhu Parekh, Gurharpal Singh, and Steven Vertovec, 165-182. London. 